International Journal of

Emerging Multidisciplinary Research

\title{
A study on knowledge and attitude towards digital health of rural population of india- Innovations in practice to improve healthcare in the rural population
}

\author{
Dr. Trisha Kumari ${ }^{1}$ \\ ${ }^{1}$ Post Graduate, Masters in Hospital Administration, Manipal Academy of Higher Education, Manipal, \\ Karnataka, India
}

\begin{abstract}
Background/Objectives: The study was prospective observational cross-sectional study conducted a tertiary care teaching hospital, Kasturba Hospital, Manipal, India. Methods/Statistical analysis: Study was conducted for a period of 3 months and convenient sampling was used for the selection of participants. A sample size of 131 patients who lived or had been living in rural area have been included in the study. Study participants were informed about the proposal and method of study. Findings: In this study, we are currently investigating various types of digital health services in India in the Indian Health Scenario, with new developments in the range of digital health for the Indian population and the areas of social insurance and usefulness in India. Investigate new developments. Improvements/Applications: Several innovations have been explained like e-health, telemedicine, virtual consultation, smart pills which are implemented in most of the urban areas and can be applied to rural areas to improve health and lifestyle of Indian population.
\end{abstract}

\section{Index Terms}

Digital health, Innovation, Technology, m-health, Telemedicine

\footnotetext{
Corresponding author : Dr Trisha Kumari

trishakumari1110@gmail.com

- Manuscript received August 20, 2019.

- Revised September 9, 2019 ; Accepted September 20, 2019.

- Date of publication September 30, 2019.

(C) The Academic Society of Convergence Science Inc.

2546-1583 @ 2017 IJEMR. Personal use is permitted, but republication/redistribution requires IJEMR permission
} 


\section{INTRODUCTION}

Digital health is a multi-disciplinary space which includes numerous stakeholders, including clinicians, analysts and researchers with a wide scope of skill in healthcare, engineering, social sciences, public health, health economics and the executives[1] . It is not about what innovation can accomplish for individuals, it's what individuals can do with innovation. India too has adopted digital health.. In May of 2016, India had tabled a resolution at WHO for mHealth, which was bolstered by more than 30 countries [2]. This unmistakably flag India's aim to be a worldwide innovator in Digital Health. Subsequent to banking, the next focus area of the Digital India programme is healthcare.

With the presentation of new guidelines and activities, for example, the Startup India campaign, and more recently the new Medical Device Rules 2017 (GSR $78 \mathrm{E}$ ) - set to take effect from January 2018 - the Indian Government has made noteworthy strides towards the development processes that impact digital health [3]. Shri Narendra Modi, Prime Minister of India had said that I consider innovation to be a way to engage and as a device that scaffolds the separation among expectation and opportunity. We should guarantee that innovation is available, reasonable and adds value [4].

\section{OBJECTIVES}

1.Current health scenario in India.

2. To investigate different types of digital health services in India.

3. Scope of digital health for the Indian population.

4. Present and clarify new advances and new developments in the field of social insurance and usability in India.

5. To investigate the advantages and difficulties of digital healthcare in India.

\section{METHODOLOGY}

\section{Participants:}

The study was prospective observational crosssectional study conducted a tertiary care teaching hospital, Kasturba Hospital, Manipal, India. Study was conducted for a period of 3 months and convenient sampling was used for the selection of participants. A sample size of 131 patients who lived or had been living in rural area have been included in the study. Study participants were informed about the proposal and method of study. The participants who refused to participate, inaccessible and more than 70 years of age were excluded from the study.

\section{Research tools:}

An online questionnaire survey was done with 131 respondents from rural areas of Karnataka. 5 rural places of Karnataka was taken into consideration which have few healthcare facilities. The respondents all equipped with their own mobile phones were considered for the study. A simple yes or no questionnaire was distributed online. 10 females and 121 males participated in the study. Simple random sampling method was used while determining the sample size. The questions included the knowledge and need of digital healthcare services in their respective rural villages.

\section{RESULTS:}

\section{Knowledge about digital health:}

The first question asked in the questionnaire was the the knowledge about digital health. 96 out of 131 responded 'Yes' to the question whereas 18 out of 131 responded 'No'. Around 17 were unsure about the knowledge of didgital health. This gives us the idea that many had knowledge about digital health in the rural population.

Table 1. KNOWLEDGe OF Digital HEALTH AS RESPONDED BY THE RURAL POPULATION

\begin{tabular}{ccccc}
\hline $\begin{array}{c}\text { Respons } \\
\text { es }\end{array}$ & $\begin{array}{c}\text { Frequen } \\
\text { cy }\end{array}$ & $\begin{array}{c}\text { Perce } \\
\text { nt }\end{array}$ & $\begin{array}{c}\text { Valid } \\
\text { perce } \\
\text { nt }\end{array}$ & $\begin{array}{c}\text { Cumulati } \\
\text { ve percent }\end{array}$ \\
\hline Yes & 96 & 73.3 & 73.3 & 73.3 \\
\hline No & 18 & 13.4 & 13.4 & 86.7 \\
\hline Maybe & 17 & 13.3 & 13.3 & 100 \\
\hline Total & 131 & 100 & 100 & 100 \\
\hline
\end{tabular}


The results were compiled which showed $73.3 \%$ had knowledge on digital health where as $13.4 \%$ had no idea on digital health. $13.3 \%$ were unsure about it.

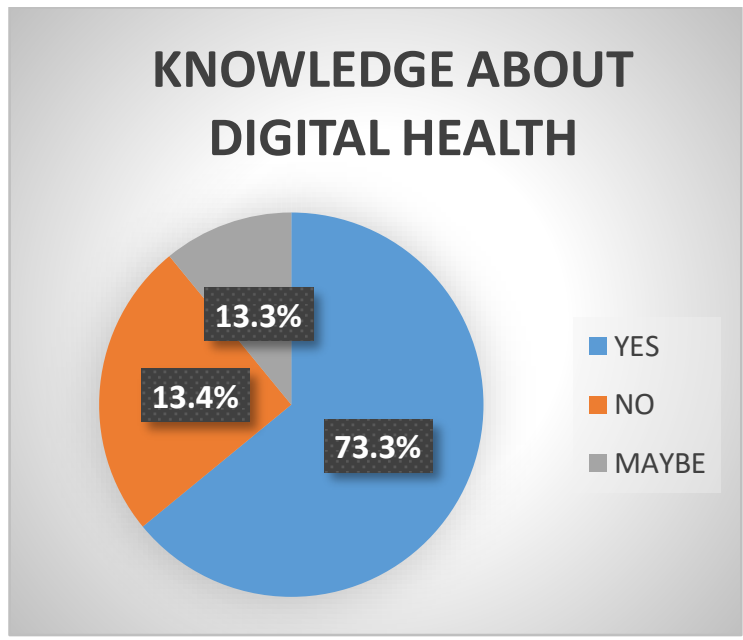

Figure 1: $73.3 \%$ of people who were surveyed had knowledge of digital health that it existed and is used in other parts of the state.

\section{Usage of digital health services:}

The second question asked in the questionnaire was the usage of digital health services. 87 out of 131 responded 'Yes' to the question whereas 26 out of 131 responded 'No'. Around 18 were unsure about usage of digital health services. This suggested that many had used digital services in the past atleast once.

Table 2: UsAGE OF DIGITAL HEALTH SERVICES AS RESPONDED BY THE RESPONDENTS.

\begin{tabular}{ccccc}
\hline $\begin{array}{c}\text { Response } \\
\text { S }\end{array}$ & $\begin{array}{c}\text { Frequenc } \\
\mathbf{y}\end{array}$ & $\begin{array}{c}\text { Percen } \\
\mathbf{t}\end{array}$ & $\begin{array}{c}\text { Valid } \\
\text { percen } \\
\mathbf{t}\end{array}$ & $\begin{array}{c}\text { Cumulativ } \\
\text { e percent }\end{array}$ \\
\hline Yes & 87 & 66.7 & 66.7 & 66.7 \\
\hline No & 26 & 20 & 20 & 86.7 \\
\hline Maybe & 18 & 13.3 & 13.3 & 100 \\
\hline Total & 131 & 100 & 100 & 100
\end{tabular}

The results were compiled which showed $66.7 \%$ had used digital services before atleast once, where as $20 \%$ had never used digital health services. $13.3 \%$ were unsure about it.

\section{USAGE OF DIGITAL HEALTH SERVICES}

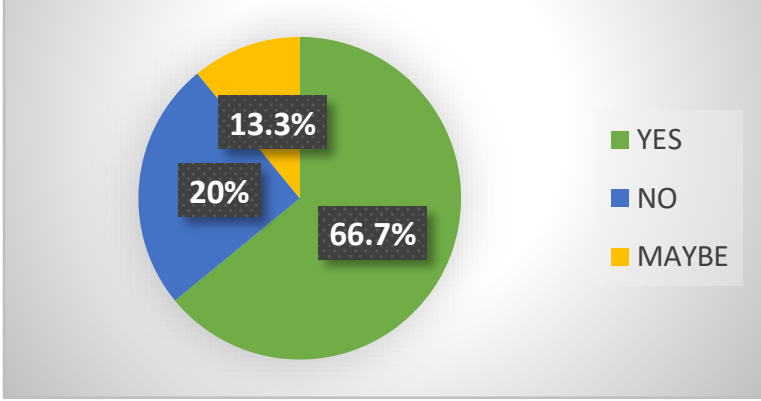

Figure 2: $66.7 \%$ of the surveyed population had tried to use or have used the digital health services once or more than once.

\section{Preferences for treatment:}

The third question asked in the questionnaire was the preferences for treatment. 90 out of 131 responded that they are comfortable with 'Real Doctor' whereas 28 out of 131 responded that they are comfortable solely on 'Virtual Doctor'. 28 people told they prefer both.

Table 3: Preferences of Using Digital heALTH SERVICES WHEN COMPARED TO CONVENTIONAL METHOD OF TREATMENT.

\begin{tabular}{ccccc}
\hline $\begin{array}{c}\text { Option } \\
\mathbf{s}\end{array}$ & $\begin{array}{c}\text { Frequenc } \\
\mathbf{y}\end{array}$ & $\begin{array}{c}\text { Percen } \\
\mathbf{t}\end{array}$ & $\begin{array}{c}\text { Valid } \\
\text { percen } \\
\mathbf{t}\end{array}$ & $\begin{array}{c}\text { Cumulativ } \\
\text { e percent }\end{array}$ \\
\hline $\begin{array}{c}\text { Real } \\
\text { doctor }\end{array}$ & 90 & 68.6 & 68.6 & 68.6 \\
\hline $\begin{array}{c}\text { Virtual } \\
\text { doctor }\end{array}$ & 13 & 21.1 & 21.1 & 89.7 \\
\hline Both & 28 & 10.3 & 10.3 & 100 \\
\hline Total & 131 & 100 & 100 & 100 \\
\hline
\end{tabular}

The results were compiled which showed $68.6 \%$ prefer real doctor and $21.1 \%$ told they prefer virtual doctor. $10.3 \%$ of respondents preferred either real or virtual doctor. 


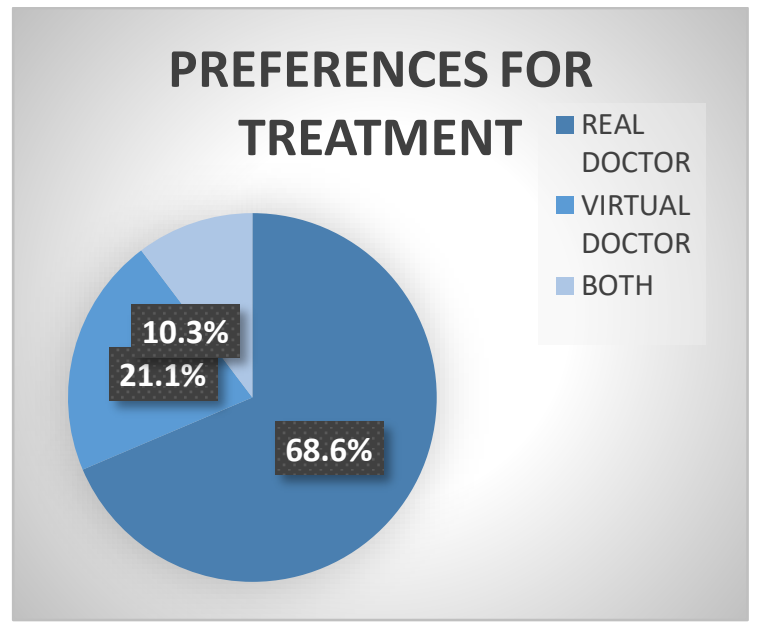

Figure 4: $68.6 \%$ of the surveyed population preferred real doctors on virtual doctors as they found it more comfortable and convincing.

\section{Services they would like to use:}

The services mentioned in the questionnaire of digital health telemedicine, m-health, sensors and gamification. The services were explained in detail to the respondents and the responses were recorded.

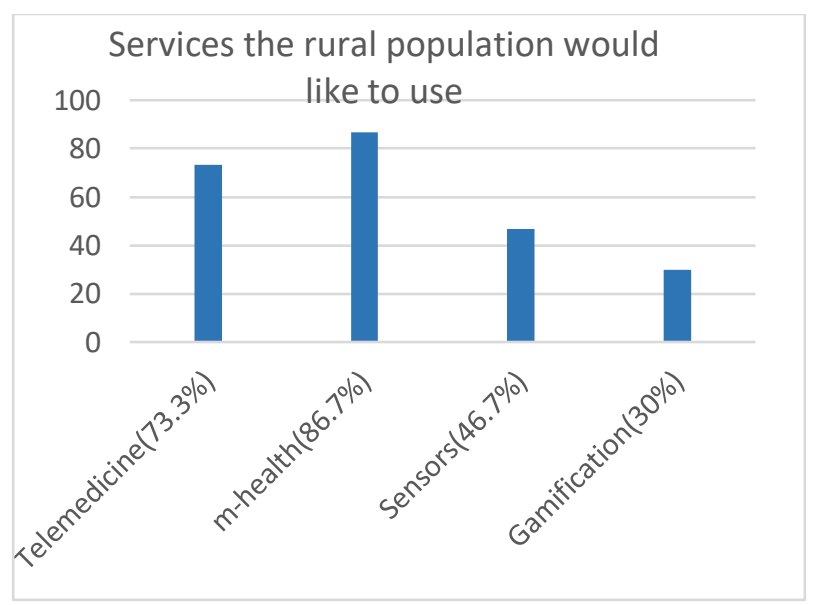

Figure 5: Services the respondents in rural population would like to use in digital health. The most preferred service to be implemented in their respective areas were m-health $(86.7 \%)$ followed by telemedicine $(73.3 \%)$

\section{Knowledge about digital healthcare services} launched by Government:

There are various apps released by the Government in India. Many apps can help people in case of emergency especially in rural areas. Knowledge about digital healthcare services launched by Government was collected to determine to see if the people are sensitized about it.

Table 4: KNOWLEdGe ABOUT Digit AL HEALTHCARE SERVICES OF THE RESPONDENTS LAUNCHED BY GOVERNMENT

\begin{tabular}{ccccc}
\hline $\begin{array}{c}\text { Respons } \\
\text { es }\end{array}$ & $\begin{array}{c}\text { Frequen } \\
\text { cy }\end{array}$ & $\begin{array}{c}\text { perce } \\
\text { nt }\end{array}$ & $\begin{array}{c}\text { Valid } \\
\text { perce } \\
\text { nt }\end{array}$ & $\begin{array}{c}\text { Cumulati } \\
\text { ve percent }\end{array}$ \\
\hline Yes & 83 & 63.3 & 63.3 & 63.3 \\
\hline No & 22 & 16.7 & 16.7 & 80 \\
\hline Maybe & 26 & 20 & 20 & 100 \\
\hline Total & 131 & 100 & 100 & 100 \\
\hline
\end{tabular}

The results were compiled which showed $63.3 \%$ had the knowledge about the digital health services launched by the Government and $16.7 \%$ told they had no idea about digital health services launched by the Government. 20\% had some idea about knowledge about the digital health services launched by the Government.

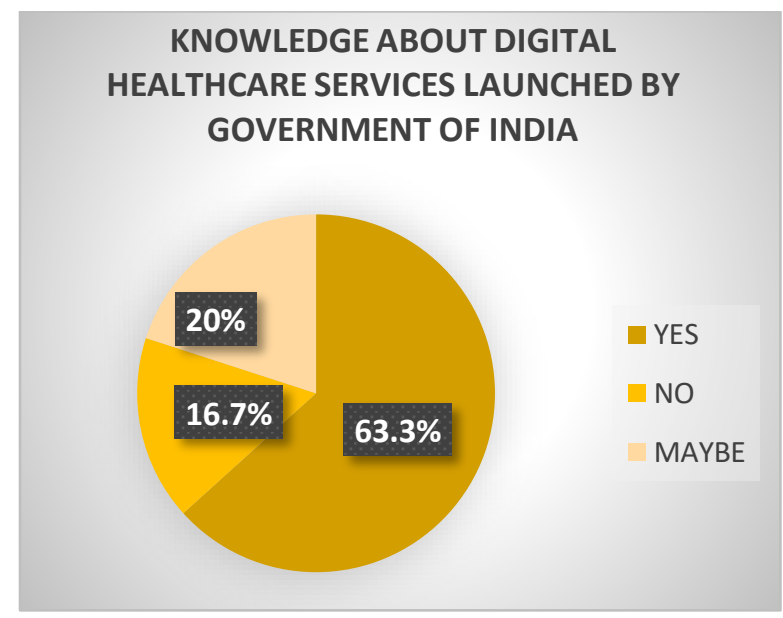

Figure 6: $63.3 \%$ of the surveyed population had idea about the digital healthcare services launched by the government for better accessibility of healthcare. 


\section{Interest in implementation of digital} healthcare services in their respective areas:

The question involved about interest in implementation of new digital healthcare services or improvement of existing digital healthcare service in their respective areas from which the respondents belonged to in the study.Out of 131 respondents, 74 answered they were interested whereas 9 were not interested. 48 were not sure about the implementation.

Table 5: INTEREST SHOWN BY THE RESPONDENTS IN RURAL AREAS IN IMPLEMENTATION OF DIGITAL HEALTHCARE SERVICES IN THEIR RESPECTIVE AREAS

\begin{tabular}{ccccc}
\hline $\begin{array}{c}\text { Respon } \\
\text { ses }\end{array}$ & $\begin{array}{c}\text { Frequen } \\
\text { cy }\end{array}$ & $\begin{array}{c}\text { Perce } \\
\text { nt }\end{array}$ & $\begin{array}{c}\text { Valid } \\
\text { perce } \\
\text { nt }\end{array}$ & $\begin{array}{c}\text { Cumulat } \\
\text { ive } \\
\text { percent }\end{array}$ \\
\hline Yes & 74 & 56.7 & 56.7 & 56.7 \\
\hline No & 9 & 6.6 & 6.6 & 63.3 \\
\hline Maybe & 48 & 36.7 & 36.7 & 100 \\
\hline Total & 131 & 100 & 100 & 100 \\
\hline
\end{tabular}

The results were compiled which showed $56.7 \%$ were interested in the implementation of digital healthcare service in their area. $6.6 \%$ were not interested in the implementation of digital healthcare service and $36.7 \%$ were not sure about the implementation.

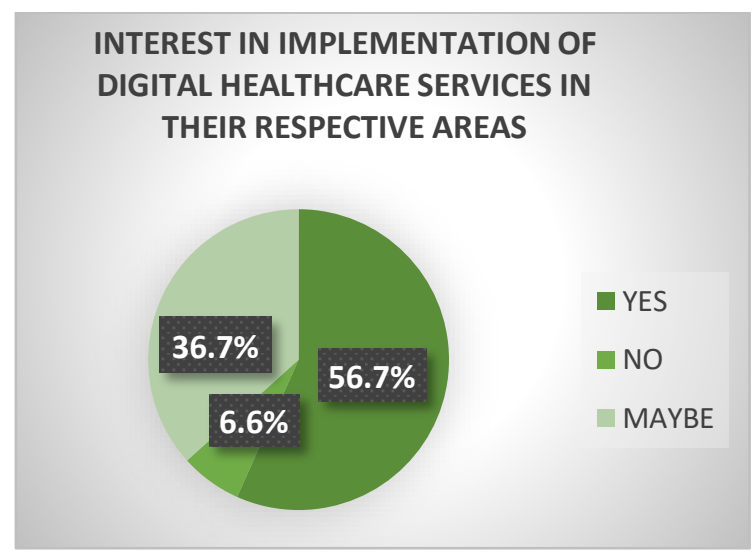

Figure 7: $56.7 \%$ of people surveyed showed interest in the implementation of digital healthcare service in their area.

\section{Major problem hindering the development of} digital health:

The questionnaire involved the major problem which was faced by the digital health for improvement in rural services. $46.7 \%$ of the respondents felt that low quality services was responsible for th people not using digital health services whereas $33.3 \%$ thought lack of knowledge was the reason for the hinderance of digital health services. Lack of trust in the digital health services was responded by $13.3 \%$ and $6.7 \%$ were due to the problems in reimbursement of health insurance for not using digital health services efficiently.

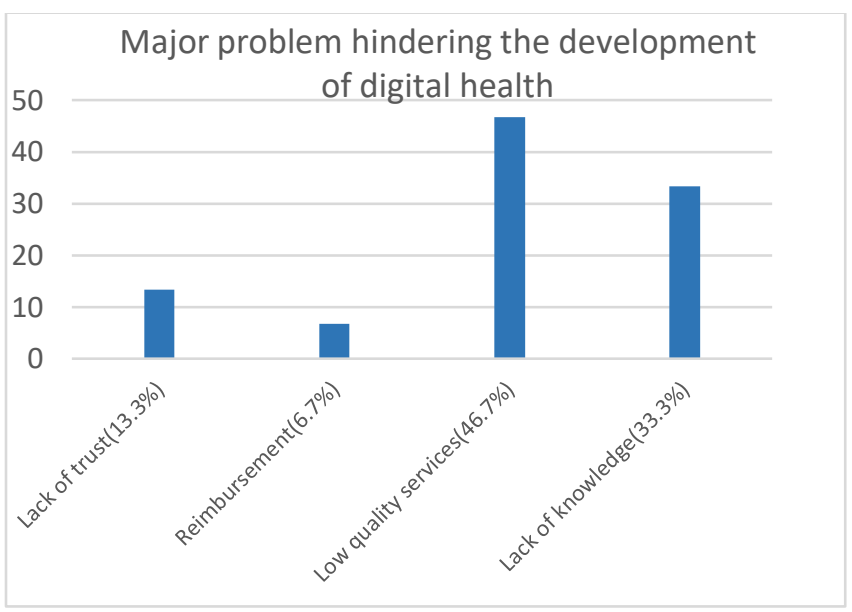

Figure 8: $46.7 \%$ of the participants were in the opinion that low quality services provided in digital health was responsible for development of digital health in the country, followed by lack of knowledge of digital health among rural population.

\section{DISCUSSION}

\section{CURRENT HEALTHCARE SCENARIO IN} INDIA:

The Indian health care services are exceptionally slanted for urban populace which is $28 \%$ of Indian populace. About one million Indians pass on consistently because of deficient medicinal services offices and 700 million individuals have no entrance to 
master care and $80 \%$ of authorities live in urban regions [5].

There has been undue deferral in actualizing egovernance and e-healthcare in India because of following reasons

(1) Absence of innovation and absence of information in the provincial areas.

(2) Cost factor.

(3) Funding framework like insurance or social security agency give give constrained inclusion.

(4) Strong expert culture among specialist's unfriendly to new ICT applications.

(5) Doctors and attendants accept on their ability than the PC.

(6) Lack of preparing in medical and nursing instruction in the field of e-health.

\section{WHAT IS DIGITAL HEALTH?}

Digital health is defined as the utilization of emerging and established tools and technologies and advances in the the areas of food, fitness, medicine, sports and wellness to improve care, bolster in general wellbeing and upgrade information. Digital health involves the use of the utilization of data and correspondence advances to help address the medical issues and difficulties looked by patients [6]. These technologies incorporate both equipment and programming arrangements and administrations, including telemedicine, web-based analysis, email, mobile phones and applications, text messages, and clinic or remote monitoring sensors. Digital health incorporates many kind of orders including including e-health, mhealth, telehealth, health information technology and telemedicine, all of which have one primary objective, to make the digital health revolution a reality.

\section{SCOPE OF DIGITAL HEALTH IN INDIA}

Digital Health is conceivably perhaps the greatest area in India inside advanced social insurance, with anticipated market size of 416 million USD in 2015, which is set to increment to 1 Billion USD INR by 2020. An ongoing report introduced that $68 \%$ of specialists in creating markets like Brazil, India, and China suggest mHealth and $59 \%$ of patients are as of now utilizing. Roughly more than 300 new businesses rose in the health care sector part in the year 2015-16 as it were. They are overcoming any issues between medicinal services specialist organizations and endclients through applications and social networks, new advances, and gadgets [7].

\section{INNOVATIONS IN HEALTHCARE:}

\section{TELEMEDICINE:}

The forthcoming field in healthcare is telemedicine in India. Its an obvious fact telemedicine has profoundly affected industry, both nationally and globally. It is the combination of Information and communication technology(ICT) with medicinal sciences [8]. Telemedicine defeats the huge difficulties which are managed in healthcare delivery for country like India. With the greater part of the Indians being bought in to cell phone with internet, the rural people can look for health care professional over a basic phone or send their reports for determination to a social health care professional who is a large number of miles away.

There are principally 3 sorts of telemedicine-

1. Store and forward telemedicine where healthcare providers share patient medical information like lab reports, imaging and other records with the doctor, radiologist or pro at another area. It has worked in modern highlights to guarantee patient confidentiality

2. Remote patient checking is another sort where expert track understanding $\mathrm{s}$ indispensable sign and exercises at a distance.

3. Real type telemedicine where video conferencing is finished by patients legitimately with healthcare professional It is led by utilizing an innovation that has been intended to secure patient rights and protection [9].

\section{Primary advantages of telemedicine in rural India:}

1. Telemedicine permits remote medical consultations that are less expensive, quicker and more effective than conventional healthcare appointments 
2.In-home checking and periodic visits to senior citizens by nursing staff and decreasing the number of hospitalization rates which thus diminishes out of pocket use.

3. Mobile Imaging centers and lab specimen kiosks which can take X-rays and perform collection can work in conjugation with remote examination labs in bigger urban regions to overcome any issues.

4. Telemedicine can play a major role in disaster management too. In disaster where the vast majority of the terrestrial communication get damaged, mobile or portable system with satellite connectivity and customized telemedicine software is ideal for disaster relief [10].

\section{Challenges to overcome to provide telemedicine to the rural population:}

Low bandwidth-slow internet connection, sometimes lack of telephone or even electricity poses major problem. Moreover, reimbursement by insurance companies is difficult as most of the health insurance companies do not cover the expenditure incurred in and hence do not prefer telemedicine. Cost of providing healthcare to the rural population is a huge task and it would require large investment as spending on healthcare sector in India is very less.

\section{2. m-HEALTH}

$\mathrm{m}$-health is the practice of medicine and public health supported by mobile devices usually through mobile phones, computers or through wearable devices such as smartwatches [11].

Apps launched by Indian government to benefit rural population:

1.Kilkari - It is an app to create awareness among pregnant women, parents and health workers on importance of ante and postnatal care on immunization. From $2^{\text {nd }}$ trimester of pregnancy till child is one year old, the app will deliver 72 times appropriate audio messages to registered mobile number on pregnancy, child and childbirth care every week.

2.Mobile Academy - Course via voice messaging upgrading the medical and health skills of ASHA.

3.m-Cessation - In collaboration with WHO and international telecommunication union has started a mobile technology for tobacco cessation. WHO-ITU's ' 'Be healthy, be mobile' 'initiative aims to reach out tobacco users of all categories. Constant text messages are sent which encourages people to quit smoking.

4.TB missed call initiative - Under this, a helpline toll free number will provide information, counselling and treatment support services for TB. Callers can give missed call to get information related to TB symptoms, address and contact details of nearest treatment facility etc [12].

$5.1 \mathrm{mg}$ - Online pharmacy with wide range of prescription and OTC medicines

Advantages of mhealth for rural India:

Tracking individual wellbeing through versatile and advanced mobile phones. m-health gives essential preventive, encourage self-care, the advancement of personal satisfaction and avert unnecessary hospitalization. It can likewise be utilized as an alert to patient, identify the area of the patient in crisis through GPS, patients assess to some data.

Difficulties to overcome to make mhealth a success in India:

Gigantic volume and divided market in mhealth, more than 1,65,000 applications are accessible in iTunes and Android application stores. The absence of mindfulness is additionally a noteworthy worry as the vast majority of the provincial individuals don't have any thought regarding offices and applications given by the Government and poor foundation and security concerns likewise represent an issue as patients don't know of protection of data. Patients additionally have a low desire with regards to mhealth as patients don't have manual manual intervention with healthcare professional.

\section{SENSORS AND WEARABLES}

Sensors and wearable permit constant physiological monitoring with decreased manual mediation and requiring little to no effort. Sensors can be incorporated into different adornments, for example, pieces of clothing, wrist groups, shoes and so forth [13]. Wearables are alluring to patients as they require no medical procedure and is as straightforward as wearing them in their everyday exercises.

Advantages: 
1.Health monitoring - records physiological data of older people.

2. Safety monitoring - to identify falls, epileptic seizures and heart attacks in older people.

3. Home rehabilitation - combination with intuitive gaming and virtual reality environments conditions to encourage locally established recovery for physiotherapy and maturing people.

4. Treatment efficiency assessment - result and productivity of the treatment is surveyed. Advancement of treatment in chronic diseases can be surveyed.

5. Early detection of disorders - Early recognition of symptoms and changes in health status can be surveyed [14].

For example, new wearable in the form of necklace called the Khushi baby is designed which monitors child immunization in rural India. The chip keeps track of the child $\mathrm{s}$ vaccinations and information is transferred to the cloud server by the health worker that has the pre-installed app on their phone. The inexpensive 1 USD waterproof computer chip replace the old paper health care system [15].

\section{Challenges to overcome:}

Inability to accurately pinpoint the cause of certain medical event. For example, symptoms reported for heart attack maybe similar to that of gastritis or pancreatitis. However, future diagnostic sensors may have much more accuracy than now and may overcome this issue. Another issue is the patients gaining medical insurance should such a device be prescribed by the physicians. If done, most of the rural people will be benefited. Moreover, most of the people may not be able to appreciate the work of the wearables because of its size.

\section{GAMIFICATION:}

Gamification is the application of game design elements and game principles in non-game contexts. In this, rewards for players who establish desired tasks or competition in the form of virtual currency is given which in turn motivates them to play more and compete [16]. For example, gamification to detect Alzheimer's was put forth by Pfizer with Akili interactive Labs to conduct a clinical trial using video game "Evo Challenge" where the patients had to navigate a series of obstacles to determine how closely they paid attention and made decisions when distracted. Even though gamification is penetrated in other sectors, it is yet to be made available in healthcare sector in India. Early detection of diseases, prevention of diseases, lifestyle and behavioral changes is possible by playing simple games and following simple instructions.

\section{CONCLUSION}

As the world now becoming more digital and adopting new technologies, India is also trying to keep up the pace by introducing new technologies at low prices. With advancing economy, growing population and booming healthcare, India has a bright future in healthcare digitalization as it is one of the emerging leaders in healthcare economy. Awareness about digital health should be created among rural population about the benefits and use of digital health. India has good potential to overcome the challenges and provide healthcare facilities at the right time to the poor and the nee

\section{REFERENCES}

[1] R. J. Widmer, N. M. Collins, C. S. Collins, C. P. West, L. O. Lerman, \& A. Lerman. (2015). Digital health interventions for the prevention of cardiovascular disease: A systematic review and meta-analysis, Mayo Clin. Proc.

[2] L. V Gangolli, R. Duggal, \& A. Shukla. (2005). Review of Healthcare in India. 2005.

[3] S. P. Bhavnani, J. Narula, \& P. P. Sengupta. (2016). Mobile technology and the digitization of healthcare, European Heart Journal.

[4] S. Sinha. (2017). IoT and Make in India: Exploring new horizons for sustainable Entrepreneurship Development in India, Circ. Comput. Sci.

[5] A. Dasgupta \& S. Deb. (2008). Telemedicine: A new horizon in public health in India, Indian J. Community Med. 
[6] R. L. Bashshur, T. G. Reardon, \& G. W. Shannon. (2000). Telemedicine: A New Health Care Delivery System, Annu. Rev. Public Health.

[7] S. Bagchi. (2006). Telemedicine in rural India, PLoS Medicine.

[8] P. Cipresso et al. (2012). Is your phone so smart to affect your state? An exploratory study based on psychophysiological measures, Neurocomputing,.

[9] G. Appelboom et al. (2014). Smart wearable body sensors for patient self-assessment and monitoring, Archives of Public Health.

[10] S. Patel, H. Park, P. Bonato, L. Chan, \& M. Rodgers. (2012). A review of wearable sensors and systems with application in rehabilitation, Journal of NeuroEngineering and Rehabilitation.

[11] F. H. McKay, C. Cheng, A. Wright, J. Shill, H. Stephens, \& M. Uccellini. (2018). Evaluating mobile phone applications for health behaviour change: A systematic review, Journal of Telemedicine and Telecare.

[12] S. Wheaton. (2017). Medical devices regulations need action to begin relay race POLITICO, Politico, 2017.

[13] A. K. Yetisen, J. L. Martinez-Hurtado, B. Ünal, A. Khademhosseini, \& H. Butt. (2018). Wearables in Medicine, Advanced Materials. 2018.

[14] S. Park, K. Chung, \& S. Jayaraman. (2014). Wearables: Fundamentals, Advancements, and a Roadmap for the Future, in Wearable Sensors: Fundamentals, Implementation and Applications, 2014.

[15] P. G. Venkat. (2016). Intermediate Assessment of the Khushi Baby cRCT: Implementation of a novel mHealth solution for vaccination record keeping in rural Udaipur, Rajasthan, India.

[16] D. Basten. (2017). Gamification, IEEE Softw., 2017. 